\title{
MANIFESTATION OF COVID-19 IN THE FORM OF ACUTE MYOCARDIAL INFARCTION (CASE REPORT)
}

\author{
Kadykova O., Koshkina M. \\ Kharkiv National Medical University, Ukraine \\ https://doi.org/10.35339/ic.7.4.180-183
}

\begin{abstract}
Acute myocardial infarction is necrosis of any myocardial mass due to ischemia. COVID-19 can be complicated by thrombosis and myocardial damage, which can lead to the deployment of a clinical picture similar to acute myocardial infarction. The material of this article is presented on the example of a clinical case. A woman aged 37 was diagnosed with an acute myocardial infarction, which later turned out to be a manifestation of a complicated course of coronavirus COVID-19 infection. This case drew attention to the absence of a clinical picture specific to this infection in the form of a damage to the respiratory system or intoxication. The case is also distinguished by the presence of a single uncharacteristic clinical manifestation of COVID-19 in the form of a cardiovascular event with elevations of the ST segment on the cardiogram and other objective data and additional research methods characteristic of acute myocardial infarction. The work also analyzed the pathogenetic mechanisms of acute myocardial infarction and cardiovascular complications of COVID-19, examined the general links of pathogenesis of these two pathological units and analyzed the causes of difficulties in their differential diagnosis. In this regard, there are unquestionably complications of differential diagnosis and the prescription of timely correct therapy. A deeper understanding of these data may improve the algorithms for diagnosing acute myocardial infarction and cardiovascular complications of COVID-19.
\end{abstract}

Keywords: COVID-19, acute myocardial infarction, thrombosis, "cytokine storm".

\section{Introduction}

At present, COVID-19 cannot be considered solely a respiratory disease that leads to severe acute respiratory distress syndrome (SARS-CoV-2) [1]. Today, there is also evidence of additional inclusion of immunopathogenetic mechanisms in its pathogenesis [2]. Hypreproduction of tumor necrosis factor- $\alpha$, interleukin- 1 and interleukin- 6 leads to development of a "cytokine storm" and multiple organ failure. Other important pathogenetic links of the infectious process can also be defined in this process: activation of the hemostasis system, intravascular coagulation and, as a result, thrombosis of vessels of mainly small caliber in

Corresponding Author:

Marharyta Koshkina, MD, PhD student

of the Department of Internal Medicine No. 2,

Clinical Immunology and Allergology named

after academician L.T. Malaya,

Kharkiv National Medical University, Kharkiv, Ukraine.

E-mail:maiorovarita2393@gmail.com the organs providing vital functions, primarily in the lungs [3].

Thus, acute myocardial infarction (AMI) is the necrosis of any myocardial mass due to ischemia of different origin, including thrombosis of coronary arteries. Key pathogenetic mechanisms include formation of stenosing atherosclerotic plaque, endothelial inflammation, disruption of fibrinolysis system, activation of bradykinin system, activation of platelet adhesion and aggregation, vasospasm, activation of reninangiotensin-aldosterone system (RAS), NO blockade, which forms the occlusion of the coronary vessel, resulting in cardiomyocyte death and formation of the morphological equivalent of AMI, the focus of myocardial necrosis [4].

In turn, myocardial damage is often registered in patients with COVID-19 disease [5]. The question of the classification of myocardial damage at COVID-19 is still disputable. Some scientists consider. that it is the morphological equivalent of myocarditis, and the others believe 
that it is a form of lesion morphologically similar to inflammation [6]. The issue of the pathogenesis of this damage is also being investigated. It is believed to be a direct consequence of the effects of the virus on the myocardium. There is also a view that this damage occurs indirectly through a number of enzymatic, hemostatic and hormonal transformations $[7 ; 8]$.

The pathogenetic mechanisms of myocardial damage in case of COVID-19 are the development of multiple organ failure due to a "cytokine storm", dysregulation of RAS, oxide stress due to hypoxia, prothrombogenic effect and microvascular inflammation [9].

Myocardial damage by COVID-19 is also largely due to the co-exchange of the angiotensinconverting enzyme-2 (ACE-2). As it has already been mentioned, at the initial stages of development of SARS-CoV-2 in coronavirus infection, activation of RAS occurs, resulting in pathological enzyme ACE-2 expression primarily in the lungs and in the myocardium. In addition, there is evidence of increased expression of endothelial fraction of ACE-2 [10]. It leads to dysregulation of peptide fractions, which ultimately leads to increased fibrosis of the pulmonary parenchyma, and in the vasocardial system ACE-2 enhances endothelial dysfunction and thrombosis. All this factors cause positioning of the heart and vessels as target organs for the COVID-19 [11].

Special attention should also be paid to development of the "cytokine storm." The pathology of ACE-2 exchange and active replication of the virus lead to the hyperproduction of a number of immunocompetent molecules, among which the key roles belong to proinflammatory cytokines [12]. Activation of cytokines normally should trigger a number of immunological mechanisms and enhance the immunological response to infection of the virus. But in the case of massive replication of the virus, the cytokine response can change according to a pathological scenario. Classical cys-transmission causes the formation of gp130 complexes, which, when bound to the membranes, can be expressed in almost any tissues and organs, primarily in the organs of the cardiovascular system. This leads to increased inflammation at the sites of expression, which, in combination with hypoxia, leads to the development of insufficient function of target organs, the development of symptoms of sepsis and multiple organ failure $[13 ; 14]$.

It should be noted that the excessive uncontrolled production of cytokines triggers a cascade of secretion of other biologically active substances, the final effect of which is the pathological changes in the coagulation units of homeostasis towards hypercoagulation and thrombophilia [15]. There is also an increase in vascular permeability due to hypoproduction of nitric oxide and inhibition of fibrinolysis. All these disorders of the hemostatic balance cause both the COVID-19 vascular and myocardial damage [16-18].

Thus, there are some common links of pathogenesis, which lead to a common clinical picture of myocardial damage in COVID-19 infectious process and in AMI [19-21]. In this regard, there are unquestionably complications of differential diagnosis and the prescription of timely correct therapy [22-25].

In order to clearly demonstrate the possibility of developing cardiovascular disorders in patients with COVID-19, an illustrative clinical case is reported. The patient agreed for publishing the data, about which the informed consent of the patient was obtained.

\section{Clinical case}

A 37-year old nonobese woman (BMI $23,2 \mathrm{~kg} / \mathrm{m}^{2}$ ) with no hypertension and cardiovascular problems in history, non-smoker admitted to the cardiology ICU with a complaints at burning pain in the sternum area, radiating into her left arm, shoulder, lasting for 1 hour, general weakness. Anginal pains appeared for the first time on the day of admission during sleep, when, due to the high intensity of pain syndrome, the patient woke up and called an ambulance. According to the ECG findings, acute coronary syndrome was diagnosed and she was hospitalized. Prehospital care was provided in full in accordance with the Unified clinical protocol for emergency, primary, secondary (Specialized) and Tertiary (Highly Specialized) care and medical Rehabilitation "Acute coronary syndrome with ST segment elevation", Order of the Ministry of Health of Ukraine № 455 (02.07.2014).

Vital signs: body temperature $-36.5^{\circ} \mathrm{C}$; peripheral O 2 saturation $98 \%$ on room air; respiratory rate of 16 breaths $/ \mathrm{min}$, heart rate of 105 beats/min, blood pressure of $110 / 70 \mathrm{mmHg}$.

Physical examination: Patient was concious and well oriented in time and space. Skin and mucous membranes were normal. No particular changes were found in body systems.

Laboratory findings: leukocytosis; elevated ALT (102.5 U/L), creatine phosphokinase (4859.7 U/L) and myocardial fraction creatine phosphokinase (619.4 U/L).

ECG: sinus rhythm and elevation of ST segment in V1-V6 leads up to $6 \mathrm{~mm}$. Acute stage 
of anterior myocardial wall infarction was diagnosed.

Ultrasonography of the heart (Echo-CG): end diastolic volume $94 \mathrm{~cm}^{3}$, end systolic volume $51 \mathrm{~cm}^{3}$, interventricular septum thickness $-0.9 \mathrm{~cm}$; left ventricular posterior wall thickness $0.9 \mathrm{~cm}$; hypoakinesia zones were installed, no dyskinesia zones were found. Aorta was $2.9 \mathrm{~cm}$, right atrium $3.1 \mathrm{~cm}$ and right ventricle $-2.3 \mathrm{~cm}$.

The diameter of the inferior vena cava $-1.5 \mathrm{~cm}$, collaborates on breath more than $20 \%$. The pericardium was normal. The pulmonary artery valve was $1.7 \mathrm{~cm}$. Ejection fraction was $45 \%$. Restrictive type of diastolic dysfunction.

Coronarography: thrombotic occlusion of the middle segment anterior descending artery (TIMI 0 ). After stenting procedure - TIMI - III.

On the 10-th day after ECG normalized, the patient was discharged with the supervision of a cardiologist. During outpatient consultation it was decided to hospitalize the patient to the cardiology department to continue the treatment. According to the standards of delivery of health care all patients must pass COVID-19 test to be hospitalized. Patient's PCR test result was positive. Thus, acute myocardial infarction turned out to be a complication of the infectious process and its only clinical manifestation.

Similar clinical data have been described in the literature. Thus, a group of researchers led by Kevin J. Clerkin describes cases COVID-19 mainly with cardiac clinical manifestations in the form of ST-segment elevation on ECG and changes in the cardiac panel of serum biochemical analysis [26].

The data on myocardial damage in COVID-19 patients have also been published by a group of researchers (Masataka Nishiga et al.), which describes the markers of myocardial damage in such patients [27].

The findings of the group of researchers from Italy show that STEMI may represent the first clinical manifestation of COVID-19, and $85 \%$ of such patients did not have a COVID-19 test result at the time of coronary angiography. They have also published the data about approximately $40 \%$ of patients with COVID-19 with STEMI, in whom a culprit lesion is not identifiable by coronary angiography [28].

This case deserves a particular attention because of the young age of the patient with MI (37 years old female) and cardiovascular events that occurred against a background COVID-19 with no clinical presentation specific for this infection, which significantly aggravated the diagnostic algorithm.

\section{Conflict of interests}

The authors of the article declare no conflict of interest.

\section{References}

1. Spuntarelli V, Luciani M, Bentivegna E, Marini V, Falangone F, Conforti G, Rachele ES, Martelletti P. (2020). COVID-19: is it just a lung disease? A case-based review. SN Compr Clin Med. 2020 Jul 28:1-6.

2. John B.Moore., Carl H.June (2020). Cytokine release syndrome in severe COVID-19. Science.2020., Vol.368, Issue 6490, pp. 473-474.

3. Li L, Zhou Q, Xu J (2020). Changes of Laboratory Cardiac Markers and Mechanisms of Cardiac Injury in Coronavirus Disease 2019. Biomed Res Int. 2020 May 26;2020:7413673.

4. Unificovaniy klininchniy protocol ekstreno`i, pervino`I (spetsializovano`i) I tretyno`I (vysokospetsializovano `i) medychno ‘i dopomogy ta medychno `i reabilitatsi $i$ "Gostriy koronarniy syndrome z elevatsieyu segmenta ST". Nakaz MOZ Ukra iny № 455 [Unified clinical protocol of emergency, primary, secondary (specialized) and tertiary (highly specialized) care and medical rehabilitation "Acute coronary syndrome with ST segment elevations." Order of the Ministry of Health of Ukraine № 455]. (02.07.2014)

5. Kevin J. Clerkin, Justin A. Fried, Jayant Raikhelkar, Gabriel Sayer, Jan M. Griffin, Amirali Masoumi, ... Nir Uriel (2020). COVID-19 and cardiovascular disease. Circulation 141, 1648-1655.

6. Massimo Imazio, Karin Klingel, Ingrid Kindermann, Antonio Brucato, Francesco Giuseppe De Rosa, Yehuda Adler, Gaetano Maria De Ferrarri (2020). COVID-19 pandemic and troponin: indirect myocardial injury, myocardial inflammation or myocarditis. BMJ Journals, Volume 106, Issue 15.

7. Yueying Wang, Zhaojia Wang, Gary Tse, Lin Zhang, Elaine Y Wan, Yutao Guo, ..., Tong Liu (2020). Cardiac arrhythmias in patients with COVID-19. J Arrhythm. 2020 Jul 26;36(5):827-836.

8. Yuki Nakamura, Masaru Shimizu, Taeka Yamaki, Kohsuke Kushimoto, Ayahiro Yamashita, Kazuma Hayase,..., Bon Ohta (2020). Myocardial injury in a patient with severe coronavirus disease: A case report. J Infect Chemother. 2020 Oct 6:S1341-321X(20)30343-3.

9. Jose R.J., Manuel A. COVID-19 cytokine storm: the interplay between inflammation and coagulation. Lancet Respir Med. 2020;8:e46-e47. doi: 10.1016/S2213-2600(20)30216-2. 
10. Chen C, Chen C, Yan J, Zhou N, Zhao JP, Wang DW (2020). Analysis of myocardial injury in patients with COVID?19 and association between concomitant cardiovascular diseases and severity of COVID-19. Zhong Hua Xin Xue Guan Bing Za Zhi. 2020;48:E008 10.3760/cma.j.cn112148-2020022500123 .

11. Matthew Z.T., Chek Meng Poh., Laurent Renia., Paul A.MacAry., Lisa F.P.Ng (2020). Tne trinity of COVID-19: immunity, inflammation and intervention. Nature Reviews Immunology. -2020

12. Ali A, Boutjdir M, Aromolaran AS (2018). Cardiolipotoxicity, inflammation, and arrhythmias: role for interleukin-6 molecular mechanisms. Front Physiol. 2018;9:1866.

13. Kozlov V. K. (2010). Tsitokinoterapiya: patogeneticheskaya napravlennost' pri infektsionnyh zabolevaniyah I klinincheskaya effectivnost : rukovodstvo dlya vrachey. [Cytokine Therapy: Pathogenetic Focus in Infectious Diseases and Clinical Effectiveness: A Guide for Physicians.] St. Petersburg: Alter Ego; 2010. p.148.

14. Dontsov A. V. (2013). Effektivnost' dalargina v korrektsii tsitokinovogo profilya u bol'nyh IBS i metabolicheskim sindromom [Effectiveness of dalargin in cytokine profile correction in patients with CAD and metabolic syndrome.] Kursk scientific and practical bulletin "Human and his health", (1), p. 48-51.

15. Kishimoto T., Akira S., Taga T. IL-6 receptor and mechanism of signal transduction. International Journal of Immunopharmacology. 1992;14(3):431-438. doi: 10.1016/0192-0561(92)90173-I.

16. Nishiga M, Wang DW, Han Y, Lewis DB, Wu JC (2020). COVID-19 and cardiovascular disease: from basic mechanisms to clinical perspectives. Nat Rev Cardiol. 2020 Sep;17(9):543-558. doi: 10.1038/ s41569-020-0413-9.

17. Madjid, M., Safavi-Naeini, P., Solomon, S. D. \& Vardeny, O. Potential effects of coronaviruses on the cardiovascular system: a review. JAMA Cardiol. https://doi.org/10.1001/jamacardio.2020.1286 (2020).

18. Pavan K. Bhatraju, Bijan J. Ghassemieh, Michelle Nichols, Richard Kim, Keith R. Jerome, Arun K. Nalla,... T. Eoin West (2020). COVID-19 in critically ill patients in the Seattle region - case series. N. Engl. J. Med. 382, 2012-2022.

19. Steven Siu-lung Li 1, Cheung-wah Cheng, Chiu-lai Fu, Yiu-han Chan, Man-po Lee, Johnny Waiman Chan, Siu-fung Yiu (2003). Left ventricular performance in patients with severe acute respiratory syndrome: a 30-day echocardiographic follow-up study. Circulation 108, 1798-1803.

20. Rojulpote C, Gonuguntla K, Patil S, Bhattaru A, Bravo PE. (2020). COVID-19 and the Heart. Colomb Med (Cali). 2020 Jun 30;51(2):e4320.

21. Guido Tavazzi, Carlo Pellegrini, Marco Maurelli, Mirko Belliato, Fabio Sciutti, Andrea Bottazzi,... Eloisa Arbustin (2020). Myocardial localization of coronavirus in COVID-19 cardiogenic shock. Eur J Heart Fail 2020:1828.

22. ESC Guidelines for the management of acute myocardial infarction in patients presenting with ST-segment elevation (2012). Eur Heart J. 2018;39:119-177. doi: 10.1093/eurheartj/ehx393

23. Sripal Bangalore, Atul Sharma, Alexander Slotwiner (2020). ST-Segment Elevation in Patients with Covid-19 - A Case Series. N Engl J Med 2020; 382:2478-2480.

24. Yenercag M, Arslan U, Dogdus M, Gunal O,.., Sen A (2020). Evaluation of electrocardiographic ventricular repolarization variables in patients with newly diagnosed COVID-19.

25. Tan Z.C., Fu L.H., Wang D.D., Hong K. Cardiac manifestations of patients with COVID-19 pneumonia and related treatment recommendations. Zhonghua Xinxueguanbing Zazhi. 2020;48:E005. doi: 10.3760/cma.j.issn.cn112148-20200213-00077.

26. Clerkin KJ, Fried JA, Raikhelkar J, Sayer G, Griffin JM, Masoumi A, Jain SS, Burkhoff D, Kumaraiah D, Rabbani L, Schwartz A, Uriel N (2020). Coronavirus disease 2019 (COVID-19) and cardiovascular disease. Circulation 2020 Mar 21.

27. Masataka Nishiga, Dao Wen Wang, Yaling Han, David B. Lewis, Joseph C. (2020). COVID-19 and cardiovascular disease: from basic mechanisms to clinical perspectives. Nature Reviews Cardiology volume 17 , p. $543-558$

28. Giulio G. Stefanini, Matteo Montorfano, Daniela Trabattoni, Daniele Andreini, Giuseppe Ferrante, Marco Ancona,..., Alaide Chieff (2020). ST-Elevation Myocardial Infarction in Patients With COVID-19. Circulation. 2020;141:2113-2116

Received: 30-Oct-2020

Accepted: 17-Dec-2020 